\title{
Different Functional Responsibility of the Small Intestine to High-Fat/High-Energy Diet Determined the Expression of Obesity-Prone and Obesity-Resistant Phenotypes in Rats
}

\author{
Z. ŠEFČÍKOVÁ, T. HÁJEK, L. LENHARDT ${ }^{1}$, L. RAČEK, Š. MOZEŠ \\ Institute of Animal Physiology, Slovak Academy of Sciences, ${ }^{1}$ Department of Pathology, \\ University of Veterinary Medicine, Košice, Slovak Republic
}

Received September 19, 2006

Accepted April 3, 2007

On-line May 30, 2007

\begin{abstract}
Summary
The objective of the present experiment was to assess the involvement of small intestine in expression of susceptibility or resistance to the high-fat/high-energy diet. The investigation was carried out in adult male Sprague-Dawley rats fed either standard laboratory diet (3.2 kcal/g, $9.5 \%$ fat) or high-fat (HF) diet (4.04 $\mathrm{kcal} / \mathrm{g}, 30 \%$ fat) for 4 weeks as well as in HF rats that were retrospectively designated on the bases of their higher or lower weight gain as sensitive (DIO) or resistant (DR) to obesity. Our results revealed in HF group significant increase in energy intake, food efficiency, weight gain and Lee's index of obesity. Moreover, in comparison with controls, a significantly increased duodenal and jejunal alkaline phosphatase (AP) and a-glucosidase activity as well as hypertrophy of jejunal mucosa (increased protein/DNA ratio) were observed in HF fed rats. In contrast, intestinal function was inversely related to energy intake or to the development of adiposity in DIO vs. DR rats. The DR rats had significantly greater AP and a-glucosidase activity and more pronounced suppression of energy intake than obese DIO rats. It indicates that the increase of enzyme activities and the lowered effectiveness of nutrient absorption might be a significant factor preventing the expression of obesity proneness. This information contributes to a better understanding of a complex interaction between $\mathrm{HF}$ diet feeding and small intestinal adaptability, which determines the energy homeostasis and predict the ability to resist or develop obesity in these phenotypes.
\end{abstract}

\section{Key words}

Diet-induced obesity $\bullet$ Intestinal functionality $\bullet$ Feed efficiency • Energy homeostasis

\section{Corresponding author}

Š. Mozeš, Institute of Animal Physiology, Slovak Academy of Sciences, Šoltésovej 4, 04001 Košice, Slovak Republic. Fax: +42155 7287842. E-mail: mozes@saske.sk

\section{Introduction}

The modern lifestyle associated with the overconsumption of palatable high-fat diet and the sedentary behavior is considered as the main cause of the worldwide increase of obesity (Stubbs et al. 2004). Although a prominent role of dietary fat in this phenomenon is suggested, the relationship between the development of obesity and the efficiency of energy utilization have yet to be clarified. In fact, high dietary fat consumption does not always lead to obesity and even a significant number of high-fat consumers could be either of normal weight or underweight (MacDiarmid et al. 1996). It could be hypothesized that the different effectiveness of nutrient absorption in the small intestine can also be reflected in the susceptibility or resistance to a high-fat diet. This is consistent with more effective absorption of the meal in the small intestine of obese subjects (Wright et al.1983, Wisen and Johansson 1992) and with the efficacy of dietary or pharmacologically induced fat malabsorption to promote weight loss in obese humans (Hollander et al. 1998).

Available animal data suggest that, like in humans, physiological processes of digestion and nutrients absorption may also be a significant contributing factor in the development of obesity. The relevance of this is supported by lower satiating effect of fats in the small intestine of obesity-prone rats compared to that in obesity-resistant rats (Greenberg et al. 1999) and by studies using the rodent models of outbred Sprague-Dawley rats fed high-fat/high-energy 
diet. These data revealed the existence of the two animal phenotypes, i.e. rats in which developed diet-induced obesity (DIO) associated with higher weight gain and enhanced food intake and diet-resistant rats (DR) with lower weight gain, retroperitoneal fat pad weight and energy intake (Levin and Keesey 1998). Moreover, in DIO rats the high-fat diet induced a significant increase in circulating levels of insulin, leptin, and adiponectin as compared to DR rats (Levin and Keesey 1998, Ricci and Levin 2003, Perez-Echarri et al. 2005). With regard to the regulation of energy homeostasis, it was found that the DIO rats displayed a significant increase in food efficiency (the ratio of weight gained to calories consumed) than DR animals fed HF diet (Chandler et al. 2005).

The mammalian small intestine contains several enzymes in the enterocyte brush border probably playing an important role in the digestion of the individual food components and their activity also varied with the dietary substrate levels. It has been proved that in rats and mice, intestinal peptidase, disaccharidase, and alkaline phosphatase (AP) activities were simultaneously stimulated with increased dietary protein, carbohydrate and fat intake (Ferraris et al. 1992, Tanaka et al. 1998, Kaur et al. 1996, Mahmood et al. 2003). Several forms of obesity in laboratory rodents were also accompanied with substantially elevated activity of intestinal disaccha-ridases and AP activity (Ramaswamy and Flint 1980, Flores et al.1990, Adachi et al. 2003, Mozeš et al. 2004). Moreover, some studies revealed that long-lasting exposure of mice and rats to a high-fat diet led to obesity associated with mucosal hypertrophy, i.e. increase in the mucosal protein/DNA ratio (Estornell et al. 1995) and with increased activity of AP in the small intestine (Mozeš et al. 2007). However, the relationship between increased intestinal enzyme activities and DIO obesity is not fully understood particularly considering the differences between DIO and DR phenotypes. It is therefore conceivable that the investigation of biochemical and functional characteristics of the small intestine may help us to understand the feeding and growth perturbations that predict susceptibility or resistance to obesity after longterm high-fat/energy diet feeding. Accordingly, the mucosal DNA, protein as well as activity of brush border bound AP, $\alpha$-glucosidase and aminopeptidase in the duodenum and jejunum were examined in DIO and DR rats (designated on the base of higher or lower weight gain) receiving HF diet and compared with rats feed a standard laboratory diet.

\section{Methods}

\section{Animals}

Adult outbred Sprague-Dawley male rats (Charles River Laboratories, Prague) were individually housed in Plexiglass cages in a temperature-controlled environment of $22 \pm 2{ }^{\circ} \mathrm{C}$ with a relative humidity of $60 \pm 15 \%$ and $12 \mathrm{~L}: 12 \mathrm{D}$ regime (light on 06:00-18:00 h). The animals had free access to a standard laboratory diet (Laboratory diet M1, Prague; $3.2 \mathrm{kcal} / \mathrm{g}$, with $26.3 \%$ energy as protein, $9.5 \%$ as fat and $64.2 \%$ as carbohydrate) and tap water.

After 2 weeks of adaptation period, rats were divided into two dietary groups: 1$)$ control group $(n=16)$ in which the rats continued on a standard pellet diet for 4 weeks, 2) high-energy group $(n=16)$ in which the rats were switched to HF diet (Research Diet 53316 Test Diet, USA; $4.04 \mathrm{kcal} / \mathrm{g}$, with $14.55 \%$ energy as protein, $30 \%$ as fat and $55.5 \%$ as carbohydrate) for 4 weeks. During this time period, the animals of both dietary groups were kept under the above mentioned laboratory conditions with food and water ad libitum. Water intake and consumption of their respective diets were monitored weekly. After 4 weeks on HF diet, nine rats with higher weight gain were designated as DIO and 7 rats with lowest weight gain were designated as DR. Between 08:00 and 10:00 control and HF rats were killed by decapitation with removal of epididymal plus retroperitoneal adipose depots and small intestinal segments. Lee's index of obesity was calculated from data $\sqrt[3]{ }$ body weight $(\mathrm{g}) /$ nasoanal length $(\mathrm{cm})$. All animal work was in compliance with the Animal Ethics Committee of the Institute of Animal Physiology SAS, Košice.

\section{Enzyme assays and chemical analysis}

For enzyme assay small $(0.5 \mathrm{~cm})$ segments were immediately removed, the lumen was rinsed in distilled water and frozen in hexane $\left(-70{ }^{\circ} \mathrm{C}\right)$. Segments of the frozen tissue (proximal duodenum and middle part of the jejunum) were cut $(8 \mu \mathrm{m})$ in the cryostat at $-25{ }^{\circ} \mathrm{C}$ and the tissue slices were transferred to glass slides and airdried.

The analysis of alkaline phosphatase activity was performed using a modified simultaneous azocoupling method (Lojda et al. 1979). The incubation medium contained $2.0 \mathrm{mM}$ naphthol AS-BI phosphate (Sigma, Deisenhofen, Germany), $0.8 \mathrm{mM}$ Hexazotized New fuchsine (Serva, Heidelberg, Germany), $20 \mathrm{mM}$ 
Table 1. Body weight, weight gain, food intake, body fat and Lee`s index in adult male Sprague-Dawley rats after 4-week exposure to control diet (control group) and HF diet (experimental groups)

\begin{tabular}{lcccccc}
\hline & $\begin{array}{c}\text { Body weight } \\
\text { (g) }\end{array}$ & $\begin{array}{c}\text { Weight gain } \\
(\mathbf{g})\end{array}$ & $\begin{array}{c}\text { Food intake } \\
\text { kcal/day }\end{array}$ & $\begin{array}{c}\text { Food } \\
\text { efficiency }\end{array}$ & $\begin{array}{c}\text { Body fat } \\
(\mathbf{\%})\end{array}$ & Lee`s index \\
\hline Control diet $(n=16)$ & $547.8 \pm 5.2^{\mathrm{a}}$ & $44.7 \pm 3.1^{\mathrm{a}}$ & $92.2 \pm 1.2^{\mathrm{a}}$ & $2.03 \pm 0.13^{\mathrm{a}}$ & $2.8 \pm 0.2^{\mathrm{a}}$ & $0.311 \pm 0.001^{\mathrm{a}}$ \\
$H F$ diet $(n=16)$ & $576.5 \pm 9.6^{\mathrm{b}}$ & $82.4 \pm 6.4^{\mathrm{b}}$ & $110.4 \pm 2.4^{\mathrm{b}}$ & $2.63 \pm 0.17^{\mathrm{b}}$ & $4.0 \pm 0.3^{\mathrm{b}}$ & $0.317 \pm 0.001^{\mathrm{b}}$ \\
$D I O(n=9)$ & $593.0 \pm 11.9^{\mathrm{b} \dagger}$ & $100.5 \pm 5.6^{\mathrm{b} \dagger}$ & $117.0 \pm 2.0^{\mathrm{b} \dagger}$ & $2.98 \pm 0.19^{\mathrm{b} \dagger}$ & $4.2 \pm 0.3^{\mathrm{b}}$ & $0.320 \pm 0.002^{\mathrm{b}}{ }^{\mathrm{a}}$ \\
$D R(n=7)$ & $555.3 \pm 12.2^{\mathrm{a}}$ & $59.0 \pm 4.4^{\mathrm{a}}$ & $102.0 \pm 2.1^{\mathrm{b}}$ & $2.19 \pm 0.20^{\mathrm{a}}$ & $3.7 \pm 0.6^{\mathrm{a}}$ & $0.314 \pm 0.002^{\mathrm{a}}$ \\
\hline
\end{tabular}

Values are means \pm SEM. Body fat (\%) represents epididymal plus retroperitoneal fat pads. Food efficiency = weight gain/calories consumed during 4 weeks. Lee's index $=3 \sqrt{ }$ body weight $(\mathrm{g}) /$ nasoanal length $(\mathrm{cm})$. Values with different superscripts in each groups are significantly different at $\mathrm{P}<0.05$ by LSD multiple comparison test after ANOVA. + significant differences between DIO vs. DR groups.

N,N-dimethylformamide (solvent of naphthol AS-BI phosphate) and $0.05 \mathrm{M}$ veronal acetate buffer. The sections were incubated at $37{ }^{\circ} \mathrm{C}$ for $10 \mathrm{~min}$ at $\mathrm{pH} 8.9$ (Mozeš et al. 1998). The analysis of aminopeptidase M activity was performed using the simultaneous azocoupling method (Nachlas et al. 1960) with L-leucyl-4methoxy-2-naphthylamide as a substrate, Fast Blue B, $\mathrm{N}, \mathrm{N}$-dimethylformamide and $0.1 \mathrm{M}$ citric acid-phosphate buffer. The sections were incubated at $37^{\circ} \mathrm{C}$ for $6 \mathrm{~min}$ at $\mathrm{pH}$ 7.0. Demonstration of $\alpha$-glucosidase (maltaseglucoamylase complex EC 3.2.1.20) activity was performed using a simultaneous azo-coupling method (Lojda et al. 1979) with 2-naphthyl- $\alpha$-D-glucopyranoside as substrate, Hexazotized New fuchsine (Serva, Heidelberg, Germany), N,N-dimethylformamide and $0.1 \mathrm{M}$ citric acid-phosphate buffer. The sections were incubated at $37^{\circ} \mathrm{C}$ and $\mathrm{pH} 6.5$ for $20 \mathrm{~min}$.

The histochemically stained slides were visualized at low magnification (obj. x 4) using Olympus microscope (BX 51) and digital compact camera (Olympus DP 50) connected with a host computer. Sections were illuminated with white light from a $12 \mathrm{~V}$ halogen lamp $(100 \mathrm{~W})$ after filtering with a $520 \mathrm{~nm}$ monochromatic filter.

Image analysis was performed by the Ellipse program (ViDiTo, Slovakia) where the gray level of each pixel was given a value in the 0-255 range. The correspondence between these gray level values and the known integrated absorbance values of the same section points was determined by the calibration. Vickers M85a microdensitometer was used for defining the standard density values of enzyme activities at the wavelength of $520 \mathrm{~nm}$ (Frederiks et al. 1987) which were required for calibration. A special semi-interactive algorithm was used to find relevant pixels along the villus length whose density was measured (Mozeš et al. 2007). The quantification of the enzyme activity (pixel intensities) was carried out along the villus length in a whole section of at least four duodenal and jejunal slides and the mean values recorded were referred to one animal.

For chemical analysis, the mucosa from the defrosted tissue segments of duodenum and jejunum was scraped off with a glass microscope slide and weighed. The mucosal samples were homogenized in ice cold PBS. The protein content was analyzed by the method of Lowry et al. (1951) using bovine serum albumin as the standard. DNA was evaluated by the fluorimetric method (Karsten and Wollenberger 1977) modified by Koppel et al. (1981). Calf thymus DNA was used as the standard. Values are presented in $\mu \mathrm{g} / \mathrm{mg}$ mucosa of duodenum and jejunum.

\section{Statistical analysis}

Statistical analyses were carried out using the statistical package Statistica 6.1 (StatSoft CR, Prague, Czech Republic). Data were expressed as mean \pm S.E.M. and the statistical significance was accepted at the $\mathrm{P}<0.05$ level. Statistical evaluation of the somatic and small intestinal responses to standard diet vs. HF diet receiving groups was carried out by one-way analysis of variance (ANOVA) and the post-hoc Fisher's LSD test was used to compare the differences between the groups. Data from the assessment of the energy intake responses from weeks 1 to 4 in rats fed a standard diet vs. HF diet rats were analyzed by two-way ANOVA with post-hoc LSD test. Pearson's R was used to assess relationships between Lee's index of obesity, fat pad weight and body weight gained on the HF diet. 
Table 2. Duodenal and jejunal enzyme activities in adult male Sprague-Dawley rats after 4-week exposure to control diet (control group) and HF diet (experimental groups)

\begin{tabular}{lcccccc}
\hline & $\begin{array}{c}\text { Alkaline } \\
\text { phosphatase }\end{array}$ & a-glucosidase & Aminopeptidase & DNA & $\begin{array}{c}\text { Protein } \\
\text { Protein/DNA } \\
\text { ratio }\end{array}$ \\
\hline & & & DUODENUM & & & \\
Control diet $(n=16)$ & $14.4 \pm 0.3^{\mathrm{a}}$ & $9.3 \pm 0.3^{\mathrm{a}}$ & $12.9 \pm 0.9^{\mathrm{a}}$ & $3.7 \pm 0.1^{\mathrm{a}}$ & $159.9 \pm 3.4^{\mathrm{a}}$ & $44.4 \pm 1.7^{\mathrm{a}}$ \\
$H F$ diet $(n=16)$ & $16.3 \pm 0.6^{\mathrm{b}}$ & $9.7 \pm 0.3^{\mathrm{a}}$ & $11.3 \pm 0.5^{\mathrm{a}}$ & $3.9 \pm 0.2^{\mathrm{a}}$ & $154.0 \pm 3.9^{\mathrm{a}}$ & $41.3 \pm 2.5^{\mathrm{a}}$ \\
$D I O(n=9)$ & $15.4 \pm 0.7^{\mathrm{a}} \dagger$ & $9.7 \pm 0.4^{\mathrm{a}}$ & $11.5 \pm 0.3^{\mathrm{a}}$ & $4.1 \pm 0.2^{\mathrm{a}}$ & $152.4 \pm 6.3^{\mathrm{a}}$ & $38.7 \pm 3.1^{\mathrm{a}}$ \\
$D R(n=7)$ & $17.5 \pm 0.9^{\mathrm{b}}$ & $9.8 \pm 0.6^{\mathrm{a}}$ & $11.0 \pm 1.0^{\mathrm{a}}$ & $3.6 \pm 0.7^{\mathrm{a}}$ & $156.1 \pm 4.2^{\mathrm{a}}$ & $44.7 \pm 4.0^{\mathrm{a}^{\mathrm{a}}}$ \\
\hline & & & JEJUNUM & & & \\
Control diet $(n=16)$ & $13.8 \pm 0.4^{\mathrm{a}}$ & $14.6 \pm 0.4^{\mathrm{a}}$ & $19.7 \pm 0.9^{\mathrm{a}}$ & $4.2 \pm 0.1^{\mathrm{a}}$ & $140.8 \pm 3.9^{\mathrm{a}}$ & $33.8 \pm 1.2^{\mathrm{a}}$ \\
$H F$ diet $(n=16)$ & $16.1 \pm 0.5^{\mathrm{b}}$ & $16.1 \pm 0.4^{\mathrm{b}}$ & $20.3 \pm 0.6^{\mathrm{a}}$ & $3.3 \pm 0.2^{\mathrm{b}}$ & $147.5 \pm 4.4^{\mathrm{a}}$ & $47.1 \pm 3.3^{\mathrm{b}}$ \\
$D I O(n=9)$ & $15.3 \pm 0.5^{\mathrm{b} \dagger}$ & $15.4 \pm 0.3^{\mathrm{a}} \dagger$ & $20.1 \pm 0.9^{\mathrm{a}}$ & $3.5 \pm 0.3^{\mathrm{b}}$ & $150.9 \pm 7.2^{\mathrm{a}}$ & $45.2 \pm 4.2^{\mathrm{b}}$ \\
$D R(n=7)$ & $17.0 \pm 0.7^{\mathrm{b}}$ & $16.9 \pm 0.7^{\mathrm{b}}$ & $20.4 \pm 0.8^{\mathrm{a}}$ & $3.1 \pm 0.2^{\mathrm{b}}$ & $143.6 \pm 4.8^{\mathrm{a}}$ & $49.3 \pm 5.4^{\mathrm{b}}$ \\
\hline
\end{tabular}

Values are means \pm SEM. Enzyme activities are given as a density values (pixel intensities) in duodenal and jejunal enterocytes at wavelength of $520 \mathrm{~nm}$. Values with different superscripts in each groups are significantly different at $\mathrm{P}<0.05$ by LSD multiple comparison test after ANOVA. † significant differences between DIO vs. DR groups.

\section{Results}

Table 1 shows that the exposure of rats to highfat (HF) diet led to a significant increase in body weight, weight gain, body fat and food intake parameters. The rats fed a HF diet had $80 \%$ higher weight gain and $40 \%$ higher final epididymal plus retroperitineal fat pads weight and significantly enhanced Lee's index of obesity as compared to controls receiving standard diet. Moreover, during 4 weeks, these dietary obese rats consumed about $20 \%$ more energy and displayed $30 \%$ higher food efficiency than the lean controls. During the same period, the DIO rats attained about $70 \%$ higher weight gain and their energy intake and food efficiency were also significantly higher than in DR-HF rats. Although the DIO rats displayed significantly increased Lee's index of obesity as compared to DR animals, the differences in body fat pad weights between these phenotypes did not fully correspond with the expression of somatic and feeding variations between these groups. Accordingly, there was very good agreement between Lee's index of obesity and weight gain $(r=0.689)$, whereas the correlation between body fat $\%$ and weight gain showed lower value $(r=0.420)$.

A comparison of energy intake between standard diet receiving control rats and rats on HF diet suggested that the energy intake in the first week was significantly higher in both DIO and DR groups (about $50 \%$ and $40 \%$ ), whereas during the next periods a different adaptive changes to this nutritional challenge have been observed. While the energy intake in DR rats substantially decreased on the level of controls after the first week, in DIO rats despite a gradual decrease of energy intake in the $2 \mathrm{nd}$, 3rd, and 4 th weeks their values remained significantly higher than in DR rats.

Moreover, a significant time $(\mathrm{F}=41.3$, $\mathrm{P}<0.0001)$, dietary $(\mathrm{F}=104.9, \mathrm{P}<0.0001)$, and time $\mathrm{x}$ diet interaction $(\mathrm{F}=12.3, \mathrm{P}<0.0001)$ was found by two-way ANOVA (Fig.1).

Changes in intestinal activities of alkaline phosphatase (AP), $\alpha$-glucosidase and aminopeptidase in rats fed the standard diet or the HF diet are shown in Table 2. Comparison between these groups indicates that in rats receiving HF diet the AP activity was significantly higher in duodenum and in jejunum and $\alpha$-glucosidase activity was increased in jejunum compared to control rats. In contrast, no significant effect of $\mathrm{HF}$ diet on intestinal aminopeptidase activity has been found. Moreover, the obese DIO and lean DR rats displayed a different susceptibility to this nutritional challenge because the HF diet elicited greater adaptive changes in DR group. As compared to standard diet receiving controls in DR rats, AP activity significantly rose by about $22 \%$ in both intestinal segments and $\alpha$-glucosidase activity in jejunum by $16 \%$, whereas the values of AP activity in DIO rats increased only by $7 \%$ and $12 \%$ in duodenum and jejunum, respectively, and $\alpha$-glucosidase activity in jejunum by $5 \%$. 


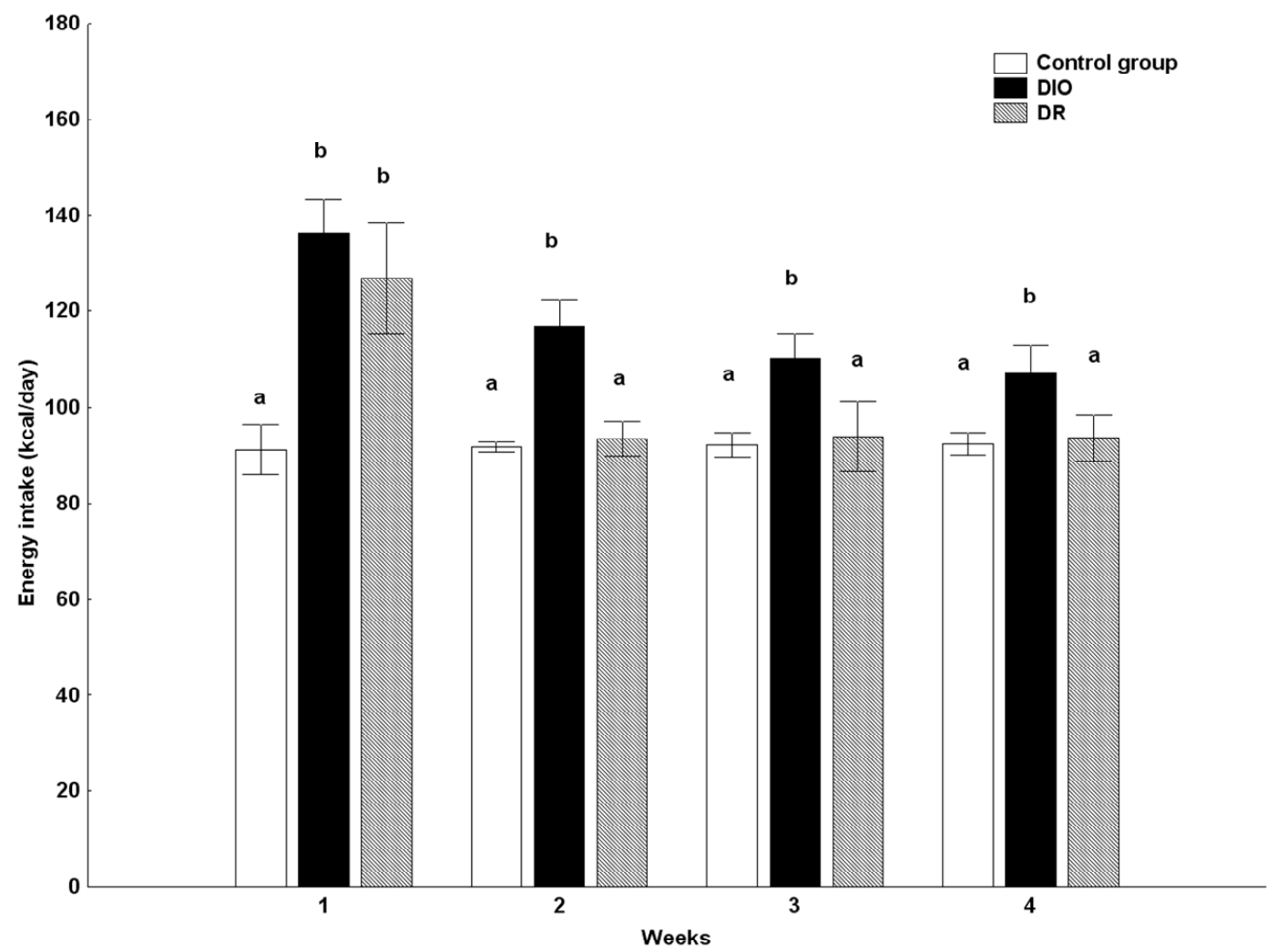

Fig. 1. Energy intake (kcal/day) of adult male Sprague-Dawley control group, DIO and DR rats fed either a standard diet or HF diet (experimental groups) for 4 weeks. Values are means \pm SEM. Bars with differing superscripts differ from each other at $P<0.05$ by post hoc test. Two-way ANOVA (time, dietary, time $x$ diet interaction) showed significant intergroup differences at $(P<0.0001)$.

Protein and DNA content in duodenum did not differ between control and HF groups (Table 2). In contrast, 4-week consumption of HF diet significantly decreased the jejunal DNA content (by about $20 \%$; in DIO rats by $17 \%$ and DR rats by $26 \%$ ) but did not alter their protein content. Due to these changes the protein/DNA ratio was significantly higher in the HF diet fed rats (by $40 \%$; in DIO rats by $34 \%$ and in DR rats by $46 \%$ ) as compared to control rats.

\section{Discussion}

Our results are in agreement with earlier findings on the development of two different phenotypes in rats after 4-week exposure to the HF diet (Levin and Keesey 1998, Chandler et al. 2005). The metabolically efficient so called DIO-rats gained significantly more body weight and became obese due to higher energy intake, while DR rats failed to reveal any significant increase in weight gain, food efficiency and Lee's index of obesity despite higher overall energy intake. Moreover, our results revealed a different pattern of the feeding response to $\mathrm{HF}$ diet in DIO and DR rats. This was apparent in later periods when DIO rats consumed more HF food than DR rats in contrast with the first week when a substantially elevated food intake has been found in both groups. From this point of view, our results suggested that the early hyperphagia is the primary reason that facilitates the expression of obese DIO and lean DR phenotypes and other factors might be important in mediation of susceptibility or resistance to a HF diet intake at that time.

Our findings suggested that the consumption of HF diet besides the enhancement of obesity had profound effects on the intestinal function of rats. As compared to standard diet fed control group this nutritional intervention significantly increased AP and $\alpha$-glucosidase activities in duodenum and jejunum and increased jejunal protein/DNA ratio in HF group. This is in line with previous reports about a similar relationship between increased body fat and small intestinal changes in HF diet fed rats (Estornell et al. 1995, Mozeš et al. 2007). However, with regard to the present data, it is not clear whether the effectiveness of nutrient absorption, the sustained increase of enzyme activity or both may be of importance for the maintenance of elevated body fat weight once dietary obesity had been established. Moreover some studies have shown that similar 
mechanisms of an increased enzyme "set point" may be involved in the modulation of body fat in several forms of obesity in which body weight and body fat changes cannot be explained by hyperphagia only. Indeed, it has been found that genetically obese mice and MSG obese rats exhibited significantly higher intestinal disaccharidase and AP activity (Flores et al. 1990, Mozeš et al. 2000) that surprisingly precedes the development of excessive body weight.

Our present results provide the first experimental evidence to support an important role of the small intestine in the induction of susceptibility and resistance to diet-induced obesity. These results indicates that the plasticity of small intestine can be perpetuated by nutritional conditions when caloric density of the diet is raised. Nevertheless, the intestinal changes were differently involved in weight gain and food intake regulation in rats with DIO and DR phenotypes. In fact, rats identified later as DR had significantly greater AP and $\alpha$-glucosidase activities and more pronounced suppression of energy intake than DIO rats after the exposure to HF diet. In mature laboratory animals the brush-border-bound AP and several disacharidases are generally considered as enzymes involved fat and glucose absorption; their activity increases after fat and carbohydrate consumption (Malathi et al. 1973, Tanaka et al. 1998, Mahmood et al. 2003). Considering the finding that enzymatic changes were proportional to the size of previous overfeeding in these different phenotypes, it is possible that the excess of overnutrition was sufficient in DR rats to induce maximal elevation of enzyme values and adjustment their activities at the higher level, but this was not the case in DIO rats. This is indicated by the fact that the higher activity of enzymes in DR group were fixed for later life, i.e. at the time when their previously enhanced energy intake lowered to the almost similar level as in lean control rats.

In light of this knowledge it is feasible to assume that small intestine of DIO rats appears to be less responsive to dietary challenge than that of DR rats. The obesity-prone DIO rats increased their weight gain and adiposity without substantial changing of enzyme activities, while DR rats reduced their weight gain and body fat accretion and these changes were reflected by simultaneously enhanced AP and $\alpha$-glucosidase activities. One of potentially interesting aspects of our present results is that the energy efficiency and size of body fat tissue observed in these groups is inversely related to the small intestine function. From this point of view, it is more probable that a higher effectiveness of nutrient absorption and lower enzyme activities may be of importance for the maintenance of obesity in DIO rats, while in DR rats increased enzyme "set point" can be a major determinant of their ability to maintain both energy homeostasis and fat pad content at lower level. Such a possibility seems to be supported by evidence suggesting an inverse relationship between intestinal AP and the rate of fat absorption. Consistently, after long-time exposure to HF diet, a faster body weight gain, elevation of serum triglyceride levels and accelerated transport of fat droplets has been observed in AP-deficient $\mathrm{KO}$ mice in comparison with wild-type controls (Narisawa et al. 2003).

Regarding the enzymatic and biochemical small intestinal changes observed in HF rats it remains unclear how the range of these responses is generated. There are the data suggesting that besides dietary influences the genetic background may play a significant role in the development of DIO and DR phenotypes. Higher body weight and obesity (despite feeding a low-fat diet) has been observed in selectively bred (3-5 generations) DIO as compared to DR rats (Levin and Dunn-Meynell 2002, Ricci and Levin 2003). When fed HF diet DIO rats became more obese than DR rats (Ricci and Levin 2003). Since human obesity is not homogenous regarding its genetic and nutritional background, the used model of outbred Sprague-Dawley rat is helpful for further exploration of the involvement of nutritional imprint in the development of diet-induced obesity. From this point of view, the present findings extend our knowledge about the interaction between small intestinal function, food intake control and the energetic metabolism and allow better understanding the intestinal mechanisms that may limit or prevent the expression of susceptibility or resistance to the high-energy diet in DIO vs. DR rats.

\section{Conflict of Interest}

There is no conflict of interest.

\section{Acknowledgements}

This work was supported by the grant 2/5141/25 and 2/6131/26 of the Slovak Academy of Sciences and by EU project QLK 1-2000-00515 / QLRT-2002-02793. 


\section{References}

ADACHI T, MORI C, SAKURAI K, SHIHARA N, TSUDA K, YASUDA K: Morphological changes and increased sucrase and isomaltase activity in small intestines of insulin-deficient and type 2 diabetic rats. Endocr $J$ 50: 271-279, 2003.

CHANDLER PC, VIANA JB, OSWALD KD, WAUFORD PK, BOGGIANO MM: Feeding response to melanocortin agonist predicts preference for and obesity from a high-fat diet. Physiol Behav 85: 221-230, 2005.

ESTORNELL E, CABO J, BARBER T: Protein synthesis is stimulated in nutritionally obese rats. J Nutr 125: 1309$1315,1995$.

FERRARIS RP, VILLENAS SA, DIAMOND J: Regulation of brush-border enzyme activities and enterocyte migration rates in mouse small intestine. Am J Physiol 262: G1047-G1059, 1992.

FLORES CA, BEZERRA J, BUSTAMANTE SA, GODA T, MACDONALD MP, KAPLAN ML, KOLDOVSKY O: Age-related changes in sucrase and lactase activity in the small intestine of 3- and 10-week-old obese mice (C57BL/6J obob). J Am Coll Nutr 9: 255-260, 1990.

FREDERIKS WM, MARX F, JONGES GN, VAN NOORDEN CJF: Quantitative histochemical study of acid phosphatase activity in rat liver using a semipermeable membrane technique. J Histochem Cytochem 35: 175$180,1987$.

GREENBERG D, MCCAFFERY J, POTACK JZ, BRAY GA, YORK DA: Differential satiating effect of fats in the small intestine of obesity-resistant and obesity-prone rats. Physiol Behav 66: 621-626, 1999.

HOLLANDER PA, ELBEIN SC, HIRSCH IB, KELLY D, MCGILL J, TAILOR T, WEISS SR, CROCETT SE, KAPLAN RA, COMSTOCK J, LUCAS CP, LODEWICK PA, CANOVATCHEL W, CHUNG J, HAUPTMAN J: Role of orlistat in the treatment of obese patients with type 2 diabetes. Diabetes Care 21: 1288-1294, 1998.

KARSTEN U, WOLLENBERGER A: Improvements in ethidium bromide method for direct fluorometric estimation of DNA and RNA in cell and tissue homogenates. Anal Biochem 77: 464-470, 1977.

KAUR M, KAUR J, OJHA S, MAHMOOD A: Dietary fat effects on brush border membrane composition and enzyme activities in rat intestine. Ann Nutr Metab 40: 269-276, 1996.

KOPPEL J, KUCHÁR S, MOZEŠ Š, BOĎA K: Nucleic acids content of some fetal and neonatal rat organs after insulin treatment. Endocrinologie 77: 95-100, 1981.

LEVIN BE, DUNN-MEYNELL AA: Defense of body weight depends on dietary composition and palatability in rats with diet-induced obesity. Am J Physiol 282: R46-R54, 2002.

LEVIN BE, KEESEY RE: Defense of differing body weight set points in diet-induced obese and resistant rats. Am $J$ Physiol 274: R412-R419, 1998.

LOJDA Z, GOSSRAU R, SCHIBLER TH: Enzyme Histochemistry. Springer-Verlag, Berlin, 1979, pp 59-70.

LOWRY OH, ROSENBROUGH NJ, FARR AL, RANDALL RR: Protein measurement with the Folin phenol reagent. J Biol Chem 193: 265-275, 1951.

MACDIARMID JI, CADE JE, BLUNDEL JE: High and low fat consumers, their macronutrient intake and body mass index: further analysis of the National Diet and Nutrition Survey of British Adults. Eur J Clin Nutr 50: 505$512,1996$.

MAHMOOD A, SHAO JS, ALPERS DH: Rat enterocytes secrete SLPs containing alkaline phosphatase and cubilin in response to corn oil feeding. Am J Physiol 285: G433-G441, 2003.

MALATHI P, RAMASWAMY K, CASPARY WF, CRANE RK: Studies on the transport of glucose from disaccharides by hamster small intestine in vitro. I. Evidence for a disaccharidase-related transport system. Biochim Biophys Acta 307: 613-626, 1973.

MOZEŠ Š, LENHARDT L', MARTINKOVÁ A: A quantitative histochemical study of alkaline phosphatase activity in isolated rat duodenal epithelial cells. Histochem J 30: 1-7, 1998.

MOZEŠ Š, LENHARDT L', MARTINKOVÁ A: Alkaline phosphatase activity of duodenal enterocytes after neonatal administration of monosodium glutamate to rats. Physiol Res 49: 269-277, 2000. 
MOZEŠ Š, ŠEFČÍKOVÁ Z, LENHARDT L', RAČEK L': Obesity and changes of alkaline phosphatase activity in the small intestine of 40- and 80-day-old rats subjected to early postnatal overfeeding or monosodium glutamate. Physiol Res 53: 177-186, 2004.

MOZEŠ Š, ŠEFČÍKOVÁ Z, LENHARDT L: Functional changes of the small intestine in over - and undernourished suckling rats support the development of obesity risk on high-energy diet in later life. Physiol Res 56: 183-192, 2007.

NACHLAS MM, MONIS B, ROSENBLATT D, SELIGAN AM: Improvement in the histochemical localization of leucine aminopeptidase with a new substrate, L-leucyl-4- methoxy-2-naphtylamide. $J$ Biophys Biochem Cytol 7: 261-264, 1960.

NARISAWA S, HUANG L, IWASAKI A, HASEGAWA H, ALPERS DH, LUIS MILLÁN JL: Accelerated fat absorption in intestinal alkaline phosphatase knockout mice. Mol Cell Biol 23: 7525-7530, 2003.

PEREZ-ECHARRI N, PEREZ-MATUTE P, MARTINEZ JA, MARTI A, MORENO-ALIAGA MJ: Serum and gene expression levels of leptin and adiponectin in rats susceptible or resistant to diet-induced obesity. $J$ Physiol Biochem. 61: 333-342, 2005.

RAMASWAMY K, FLINT PW: Effect of genetic diabetes on enzymes of mouse intestinal brush-border membrane. Am J Physiol 238: G114-G118, 1980.

RICCI M R, LEVIN BE: Ontogeny of diet-induced obesity in selectively bred Sprague-Dawley rats. Am J Physiol 285: R610-R618, 2003.

STUBBS RJ, HUGHES DA, JOHNSTONE AM, HORGAN GW, KING N, BLUNDELL JE: A decrease in physical activity affects appetite, energy, and nutrient balance in lean men feeding ad libitum. Am J Clin Nutr 79: 6269, 2004.

TANAKA T, KISHI K, IGAWA M, TAKASE S, GODA T: Dietary carbohydrates enhance lactase/phlorizin hydrolase gene expression at a transcription level in rat jejunum. Biochem J 331: 225-230, 1998.

WISEN O, JOHANSSON C: Gastrointestinal function in obesity: motility secretion, and absorption following a liquid test meal. Metabolism 41: 390-395,1992.

WRIGHT RA, KRINSKY S, FLEEMAN C, TRUJILLO J, TEAGUE E: Gastric emptying and obesity. Gastroenterology 84: 747-751, 1983. 